\title{
Sketchup and digital modelling for Classics
}

Book or Report Section

Accepted Version

Nicholls, M. (2019) Sketchup and digital modelling for Classics. In: Natoli, B. and Hunt, S. (eds.) Teaching Classics with Technology. Bloomsbury, London, pp. 131-144. ISBN 9781350110939 Available at http://centaur.reading.ac.uk/85742/

It is advisable to refer to the publisher's version if you intend to cite from the work. See Guidance on citing.

Publisher: Bloomsbury

All outputs in CentAUR are protected by Intellectual Property Rights law, including copyright law. Copyright and IPR is retained by the creators or other copyright holders. Terms and conditions for use of this material are defined in the End User Agreement. 


\section{CentAUR}

Central Archive at the University of Reading

Reading's research outputs online 


\section{SketchUp and digital modelling for Classics}

\section{Matthew Nicholls}

There is a satisfactory and available power in every one to learn drawing if he wishes, just as nearly all persons have the power of learning French, Latin or arithmetic, in a decent and useful degree.

Ruskin, The Elements of Drawing, 1.3.

In recent years the representation of the ancient past using digital reconstructions has become a commonplace of television documentaries, museum and archaeological site guides, and computer games, and is becoming increasingly common in academic projects. By 'digital reconstruction' I mean here a three-dimensional (3D) model of a structure, space, or environment created inside a computer by using modelling software. Such models can then be used to generate a still image or animation as well as many other possible outputs, some of which we will encounter later in this chapter.

My own reconstruction work is chiefly concerned with the city of Rome as it appeared in the imperial period. My work on individual structures, which began with the city's public libraries, has grown over time into a model of the entire city of Rome as it appeared around 315 CE. Researched and created from a wide range of archaeological, literary, numismatic, epigraphic, and artistic evidence, this model contains hundreds of thousands of separate elements, including many buildings with interior and exterior detailing good enough to sustain ground-level 'exploration'. 


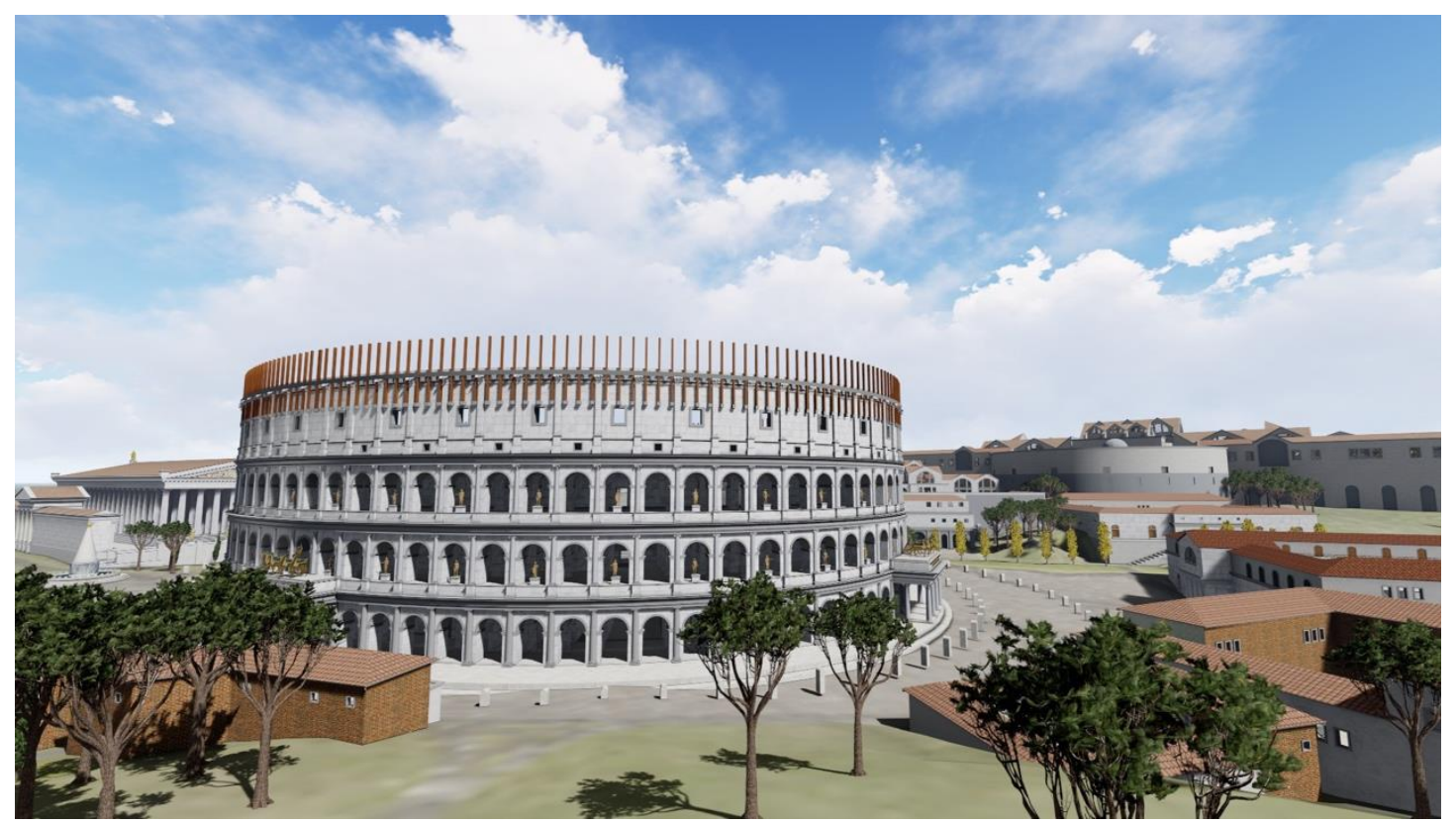

Figure 1: The Colosseum and its surroundings, looking towards the Esquiline hill - an image from the author's large digital model of ancient Rome. (C) Matthew Nicholls, University of Reading, 2018.

Research applications of this work include the study of sightlines within and between monuments, and the effects of solar illumination at different times of day and year (Nicholls 2016 and 2018, Russell 2014). This chapter is chiefly concerned with its teaching applications, however, and these are almost limitless. I use still or moving images from my digital models to illustrate lectures, articles and book chapters, public and outreach talks, field trips to Rome, and more. On large screens I 'walk' or 'fly' around the model in real time with students. Since 3D model content of this type is becoming ever easier to share, or to adapt to new forms of use, I have also made elements available in online 3D sharing platforms where users can explore buildings for themselves, used it as the basis for a free Massive Open Online Course (or 'MOOC') which has now been taken by 27,000 people, experimented with 3D printing and virtual reality, licensed the model for adaption in television documentaries, smartphone apps, and a computer game, and more. 
The overall point is that 3D content, once made, can be used, shared, and explored in many different ways that lend themselves to imaginative use in teaching contexts.

Digital reconstructions of this sort, therefore, have enormous potential for research and teaching in a field like Classics. As I intend to show here, they can now be created in software that is cheap and user-friendly enough to be amenable to use by the non-specialist. This brings digital reconstruction within the reach of research and teaching projects that do not have the resources for professional-grade software or expertise. My own background, for example, is in Classics. I am a researcher and educator in ancient Roman history, not a professional in the field of digital visualisation. I created much of the work described in this chapter without any formal training, using free or cheap software - in particular, the free 3D modelling software SketchUp - that will run on most standard computers.

It follows that other academics and teachers could do the same, and further, that their students could be taught to create models of their own, as I describe below. Though it is certainly helpful to begin with an aptitude for visualising 3D forms, and a certain facility with computers, these are not essential. A skillful or patient modeller can always reach new levels of accuracy and detail, but a very simple model can itself be a useful illustrative or teaching tool; and almost anyone can learn to make such models in software like SketchUp in a relatively short period of time (hence the epigraph from Ruskin with which this chapter opens).

Though I would like to encourage readers to experiment with their own models, it is also the case that huge online repositories of free content now make it easy to use this sort of material in teaching without having to create it for oneself. As well as my own work, there are many other ancient world 3D reconstruction projects to explore, like Rome Reborn, the Digitales Forum Romanum project of the Humboldt University in Berlin, Byzantium 1200, Virtual Amarna, and 
many more. SketchUp's own integrated '3D warehouse' contains millions of user-generated models, all of which can be freely downloaded and edited. At the time of writing, these free models included over 150 versions of the Colosseum in Rome, and nearly 90 versions of the Athenian Acropolis. The quality of these models varies widely, of course, but many excellent models are available. Specialist 3D platforms like SketchFab contain millions more models, freely explorable within any internet browser on desktop and mobile devices or in virtual reality headsets. These include models made by users, but also many contributed by an increasing number of museums and galleries, bringing high-quality annotated models of world-class artefacts into the classroom for virtual handling.

Digital reconstruction is predominantly a visual domain, of course, but other sensory inputs and outputs are increasingly possible. 3D printing is becoming commonplace in schools and universities, allowing tangible physical versions of buildings, vases, or statues. Virtual reality, delivered through a headset, brings proprioception and movement stimulus as well as proper stereoscopic 3D to a user's immersive experience of architectural environments: the effect can be very striking, adding in particular an instant intuitive appreciation of scale that can be hard to gauge on a flat computer screen. It is already possible to put a class of students into an immersive 3D environment to explore in real time - I have experimented with the Roman Forum space and with ancient theatre buildings - and as virtual reality equipment becomes more widespread, with the games industry driving technological innovation, this should become cheaper and easier to do. Augmented reality, on the other hand, allows a model to be projected into a real-world space such as a classroom table-top via the screen of a smartphone or tablet (try, for example, free apps like Augment and Kubity). Meanwhile, experiments with auditory and even olfactory modelling are allowing other senses to supplement sight. 


\section{Using digital models in teaching}

If we limit ourselves for the present to using only standard current classroom technology reasonably up-to-date computers, a projector or digital whiteboard, and perhaps tablets - digital models still offer tremendous potential for teaching topics in (say) ancient architecture. Different levels of engagement are possible. At the simplest level, digital 3D content of the sort outlined above can simply be used to produce illustrative material, in the form of still pictures or animations, to use alongside other imagery like photographs or ground plans. Digital models have particular advantages even at this relatively basic level of engagement, because they can provide a vivid and accessible proposition of the appearance of an ancient space or building, which can be more intuitively comprehensible for some students than the traditional 2D ground plans or black and white line drawings often used to illustrate ancient architecture.

A digital 3D model is particularly useful in this way because an almost infinite variety of images can be generated by positioning the virtual viewpoint or 'camera' anywhere in the space around or within it. The same model can, therefore, generate both a scaled plan view and a 3D view in which elements of height, depth, and volume are visible, thus combining the advantages (and mitigating the heuristic limitations) of planimetric and perspectival views. Animated sequences like fly-throughs can be automatically generated by moving the 'camera' through space, or around an object, and parameters like lighting, color, and transparency can all be controlled.

This ability to control and change viewpoint brings us to a deeper level of engagement with ideas about space and architecture. A model in SketchUp can be explored and edited on the screen, while the apps named above allow a digital object at least to be spun, positioned, and scaled. Navigating and manipulating digital models in this way, whether on a computer or a hand-held 
device, is immediately more engaging than just looking at images of them, and can encourage students to think critically about ways of viewing and perceiving ancient objects, buildings, or spaces, working out how ancient visitors used, moved through, or experienced them. This sort of approach complements current directions in scholarship on ancient cities and architecture, in which an emphasis known as the 'spatial turn' is being placed on how ancient spaces were experienced, considering, for example, questions of movement, appearance, sightlines, topography, social interactions, streetscapes, processions, and performances of various types. The scope of a digital model for visualising an ancient building or space from any point of view, and for moving through it, enables these sorts of questions to be considered both accurately and intuitively; simply put, we can step 'into' an ancient space and look around (acknowledging always the limitations of whatever model we might be using), a mode of investigation which is not possible in other media. Within the same model, we might for instance contrast a conventional plan or overhead view with the ground-level experience of a visitor, considering how buildings might have been designed, how ancient writers might conceptualize or describe them, how they actually appear on the ground or function in practical terms, and how they relate to their surroundings and to each other when seen from a distance. We can also set buildings in their wider context of landscape and neighborhood, generate plan views, transparencies, elevations and sections relatively easily from the same base model, superimpose ancient buildings onto modern map views, and so on. 

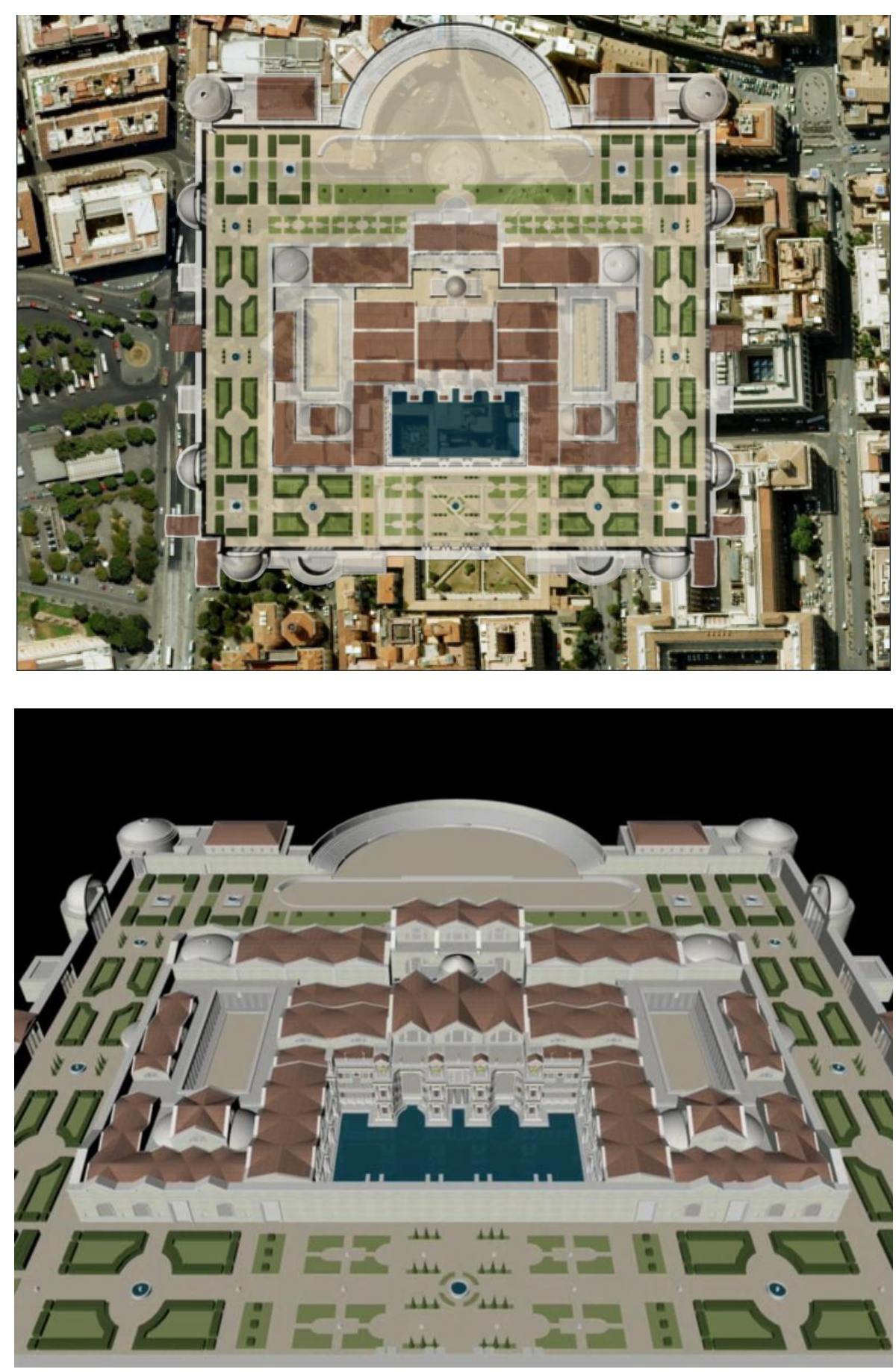

Figure 2: Two views of the same digital model of the Baths of Diocletian in Rome - an overhead view superimposed on an aerial image of the modern city, and a perspectival view showing height, volume, and elevation detail. (C) Matthew Nicholls, University of Reading, 2018

These types of enquiry or activity are possible with ready-made content from the sources named above, but a still deeper level of engagement comes when students make their own digital 
models; I describe my own experience of teaching students to do so below. The process of making one's own reconstructions necessitates a complete consideration of the structure or space in question, as gaps in knowledge, evidence, or thought quickly become evident when they show up as blank spaces in the model. Every click of the mouse becomes a decision point, grounded where possible in evidence or, where that is not possible, in reasonable conjecture. The task of making a digital model therefore encourages critical thinking about the reconstruction process as a way of handling incomplete evidence, making hypotheses or arguments about the past, and representing those visually. This is a valuable complement to the traditional textual modes of research and assessment in a discipline like Classics, which embraces numerous visual subject areas in material culture, architecture, and art history, but typically asks students to make hypotheses and arguments in a written form like an essay. The methodological similarities and differences inherent in a visual reconstruction exercise can be illuminating, as we will see.

An endless range of activities becomes possible with a class of students who are able to generate their own models, or to discover and explore ready-made 3D content: they could be asked to make a building model from a textual description, fresco, archaeological ground plan, or coin image; to think about the different experiences of a building from different points within or outside it; to visualise elements of an ancient itinerary like Ovid's or Martial's tours of Rome; to experiment with the effects of color and lighting, crowds and empty space, stillness and movement; and no doubt to invent - as my students have frequently done - creative investigatory or presentational uses for digital model content that had not occurred to their instructor.

How are such digital models made? 
A variety of modelling software is available, adapted to different sorts of task and user. Readers might find their own favorites, but my own work is largely done in SketchUp, an elegant and simple 3D modelling program. Elsewhere in this volume Jessie Craft discusses his excellent work using Minecraft (see also Craft 2016). While Minecraft uses the placing of ready-made building blocks to create structures - like digital Lego - SketchUp is essentially a drawing tool, using lines to create bounded 2D and 3D shapes that can exist in any form and combination, enabling its users to create an almost infinite variety of 3D digital content at whatever level of detail they wish. The basic toolset is simple enough: a line tool draws a line between two points chosen with mouse clicks inside the modelling environment; a closed loop of coplanar lines creates a 2D surface (a square, say, or a circle); these can be 'push-pulled' or extruded into 3D shapes (a cuboid or a cylinder), which can then be further extended, partitioned, colored, moved, sectioned, scaled, rotated, duplicated, and so on. Images can be imported into the program, including ground plans to use as references for modelling or as 'textures' (a brick pattern, say, or plaster) that can be painted onto surfaces to enhance a model's appearance.

Using this simple basic toolset, even an inexperienced user can generally create simple but useful models very quickly. Conversely, almost any amount of time and effort can be invested to produce larger and more detailed results: my own model of Rome has been around a decade in the making, and work continues. Here, for example, are two SketchUp models of the Temple of the Deified Claudius in Rome. Both require an understanding of the evidence for the building from preserved remains, published archaeological ground plans, literary descriptions, and so on, and the interpretative reconstruction of those remains, but this sort of knowledge is already within the domain of the ancient historian or archaeologist with an interest in Roman architecture. 


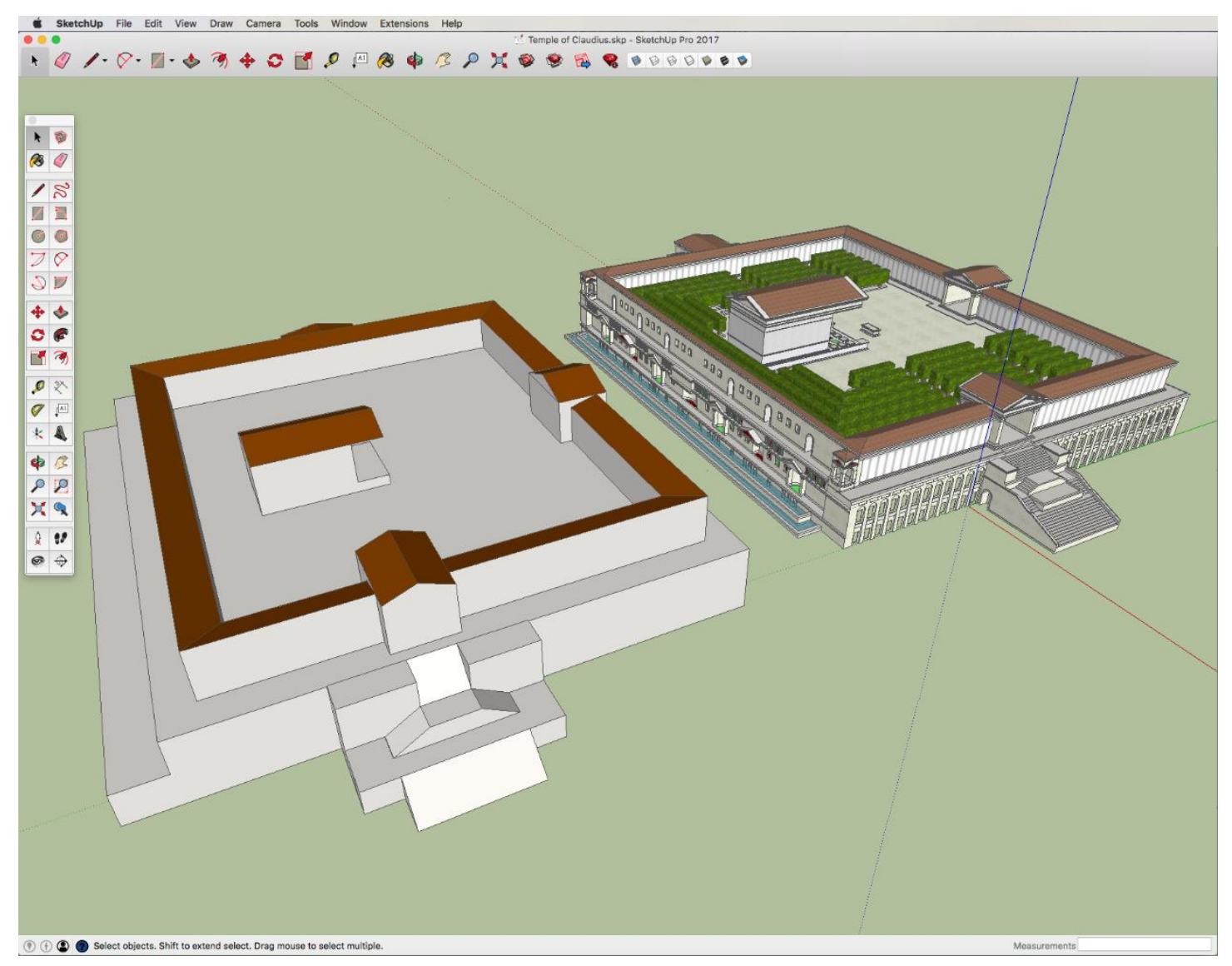

Figure 3. Two models of the Temple of the Deified Claudius in Rome, made and viewed in SketchUp. (C) Matthew Nicholls, University of Reading, 2018.

In terms of modelling skill and time, the simple schematic model on the left took approximately five minutes to make using only a subset of the simplest drawing tools in SketchUp (line, erase, push-pull, move, paint bucket). The more detailed model to the right took several days' work and uses a wider repertoire of tools and actions, but all still within the user-friendly native toolset of the free version of the software. Either could be useful for classroom explorations, as a stimulus for questions like: what is the view of the complex from below? Can you tell that it contains a temple? How does the view change as you 'climb' the monumental stairs? The simpler model could be made by many students within an hour or so of starting to use the software for the first time: when I teach SketchUp workshops, I tend to see beginner students - from primary school 
to undergraduate level - racing ahead of my tuition to explore what the different tools do; later on, when we get to more complex functions, the pace settles down.

This is because, like Minecraft modelling, SketchUp is relatively easy and (importantly) fun to use from the outset. Professional-grade software like AutoCad or 3DS Max can generate more complex and sophisticated models, but comes with a correspondingly steep learning curve. I suggest that for non-specialist use in the context of teaching a subject like Classics, a free and simple tool like SketchUp is ideal because it is not off-putting to the complete beginner: in fact, I - and many of my students - have found that it is actually annoyingly addictive. Beginners encouraged by this article to try digital modelling might well find the same: the rewards of success come early and often enough to encourage persistence to higher levels of competence and fluency.

As SketchUp has become a popular tool with millions of users worldwide, it is well supported by online resources including the 3D Warehouse mentioned above, plugins, extensions, and tutorials to support a user's development. It can also import and export a very wide variety of file formats, which means that content made there can be reused in lots of other digital contexts, including all those suggested above, and vice versa.

Though SketchUp is capable of very detailed results - it is used by many architects, landscape designers, and cabinet makers, for example - it has limitations. It could not hold my entire model of Rome, which I create and export in smaller sub-units and assemble in more complex and expensive software like Lumion and Cinema 4D. These are able to deal with massive models, and to 'render' still or moving images by simulating the effect of light and shade on the various natural and man-made surfaces in the city, achieving a more convincing appearance. For most uses, however, and certainly for beginners or as part of a larger educational project, tools like SketchUp are more than sufficient. 


\section{Teaching students to make their own models}

My own experience of learning to create digital models as a non-specialist suggested that I might be able to involve students in making similar models of their own. I was encouraged to do this by students at the University of Reading who saw pictures of my model that I used in my lectures (that first, fairly simple level of engagement described above) and wanted to know how I had made them; when I described the process, they asked if they could try for themselves. This opportunity to develop a new style of teaching seemed worth taking for a number of reasons.

Firstly, it seemed likely that it would be tremendous fun for both educator and students, which is not a negligible consideration. I like making 3D models: the software is enjoyable to use, the results are very satisfying, and it offers an avenue for visual and creative expression that is not always possible within the conventional disciplinary confines of a Classics degree. It seemed likely that students would find the same, and this has in fact proven to be the case, shown anecdotally in the fact that the classes are always a pleasure to teach, and more formally by strong expressions of positive feedback during and after the course, and by the quality of the submitted work. Many students are attracted to studying the ancient world in the first place by their experience of computer games, films, documentaries, or museum exhibits which make use of digital reconstruction, and I discovered a strong appetite to find out more and to have a go for themselves.

Secondly, offering a course of this type fitted with certain pedagogical aims of my department and university, which are keen to get students actively involved in 'enquiry-based learning'. Towards the latter stages of their degree, our aim is to encourage students to develop their own research topics and the skills, problem-solving, and knowledge needed to address them, with the lecturer acting more as a facilitator than (only) as a source of information. The goal is to 
encourage initiative and to deepen the students' acquisition of knowledge, since it is acquired in projects of their own devising. A task like researching and creating a digital model of an ancient building lends itself very well to this sort of approach because it is very open-ended: as I hope the material above has started to show, and as we will see below, digital models come in a wide variety of types and can be used to address many different sorts of questions, so an important initial step is for students to determine what sort of model they wish to make and why.

Thirdly, an exercise of this type necessarily introduces a number of new skills and aptitudes that are highly distinctive within a Classics degree. Many of these - not only the use of the digital modelling software itself, but also the associated skills of image research and manipulation, file management, and visual presentation of material - are valuable 'transferable' digital skills that are important for a non-vocational discipline like Classics to be able to demonstrate in at least some of its teaching; several former students have gone on to make use of this distinctive experience in their first job interviews (and sometimes first jobs) after graduation. The necessarily visual learning style is also unusual within a Classics degree and appeals to a wide variety of students, including those with some learning disabilities who are able to flourish in a non- or at least not solely verbal form of assessment.

I therefore decided to create an undergraduate digital modelling module (at Reading, a 'module' is a unit of undergraduate study, typically worth 20 of a year's total of 120 credits, and often taught in the course or one or two terms' instruction). The module was based on creating digital reconstructions of buildings from the Romano-British town of Silchester, local to Reading and excavated by our own Archaeology department over recent decades. Silchester was inhabited from at least the first century BCE to around the sixth or seventh centuries CE. It began life as the stronghold of an iron age British tribe, and then became a regional Roman capital in southern 
Britain, at an important junction point in the island's road network. At its height it was an important town, with impressive public buildings (a forum with a basilica, a bathhouse, an amphitheatre), an imposing wall circuit with entrance gateways, and a large number of houses whose furnishings, including impressive mosaic decorations, survive and are displayed in our town museum.

A town like Silchester thus offers a good basis for a digital reconstruction module because a lot of information is readily available, from Victorian and Edwardian excavation plans and publications, to the museum artefacts and standing remains of the walls and amphitheatre, to more modern and intensive excavations. The site is compact, but contains a wide variety of building types, with good comparable examples from elsewhere in the Roman empire to help supplement the foundations which survive at Silchester, all interesting, but none so vast or known in such detail that making a model becomes a daunting task for a beginner. There is a decent if dated singlevolume guide to the site (Boon 1974) with just enough information on each building type to give students a good start, and a well-developed body of more detailed scholarly literature, including a meticulous compilation and mapping of all excavation data (Creighton 2016). Since finding and assessing the usefulness of the available evidence is a fundamental part of creating a digital reconstruction, this well-defined body of material is an excellent starting point. To avoid wear and tear on fragile Victorian pull-out maps and journal articles I arranged for the library to make scanned copies available in our virtual learning environment (VLE); otherwise, all the necessary material was readily and immediately available.

The module, 'Digital Silchester', is taught in two-hour classes in a computer lab on university PCs running a free educational licence of SketchUp. A free in-browser version of the software has now removed the need for installing anything on networked machines: any computer 
with an internet connection can run it, including students' own laptops, though a proper threebutton mouse vastly improves the user experience.

Students are encouraged to download and experiment with the software before the start of term, but no prior knowledge or experience is assumed. We start, however, not with software skills, but with introductory lectures about the historical context of the site, and the Romans in Britain. We then move on to questions of methodology, tools, and goals. At an early stage in the module I tend to ask students about their ambitions for the digital models they will be creating, and their initial answers are fairly uniformly variations on the concept of 'realism'. But that is a rather more labile quality than might be supposed. In general, the students aim at first to create the sort of photo-real impression of verisimilitude that computer games and television reconstructions can display. This is possible to do within the software we use, but one aim of the module is to encourage a more critical interrogation of this frequently encountered mode of visual interpretation, in the same way that we train Classicists to be critical readers of texts. Documents like the London Charter seek to establish ground rules for the practice and 'ethics' of digital reconstruction, given its potential for creating images with a high superficial degree of convincingness, and it is important to include a similar element of methodological reflection in a module taught within the disciplinary context of Classics, Archaeology, or Ancient History.

Questions worth asking include: does apparent verisimilitude necessarily equate to accuracy, or intellectual rigour? How do we link what we show in the model to what we know from our research? What, in fact, do we know about the site? What do we not know? Can and should we represent in our models doubtful or variant interpretations of the evidence? We also think about ways of presenting digital reconstruction: what sort of information do we actually want to convey, and how might this be affected by styles of presentation? The software can generate 
whatever we wish: a 'photo-real' mode of presentation certainly, but also something more like a graphical illustration, or a cross section, partial transparency, cutaway, or plan. We could choose to show a scene inhabited and full of furniture and the clutter of daily life if we are interested in investigating questions of social history or, like my Rome model, empty, as an architectural macquette, if we are more interested in architectural and topographical questions. We could show a building 'realistically' (that is, from the ground-level perspective of an ancient visitor), but might find it more useful to choose an 'unrealistic' viewing mode, such as an overhead view with the roof removed, like a dolls' house, to reveal the interior. We could aim for multiple different viewing possibilities, including different camera positions and different types of content (e.g., people, furniture, roofs, colors, periods of time, annotation labels) on layers that could be turned on and off, or animated in sequence. All of this works much better if planned carefully in advance, before starting to make the model, so it is important to begin by asking what kind of claims to authenticity or reliability these different types of model make, and how they present information to their audience. This discussion helps to build a degree of visual critical literacy in students, which they can bring to bear on visual material they encounter elsewhere in their studies.

After covering these questions, we move into masterclass-style SketchUp workshops on practical modelling techniques. I connect my computer to a projector, so I can show the students how to use various tools within the software as they follow along. I also reinforce important points, or address student requests, with short narrated screengrab videos in our VLE to make the most efficient use of classroom time. Towards the end of the module I try to allow time for troubleshooting work on students' individual models.

The assignments for the module consist of a small interim model with written commentary, to be handed in at the mid-point of the term and worth $20 \%$ of the overall mark, and a larger model 
with commentary due at the end of term, worth the remaining $80 \%$. The split in the value of the two pieces was intended to force early engagement and competence with the software: while a student can sometimes scrape a passing mark if they leave work on an essay to the last minute (though one is loath to admit it), a similar attempt to put off any digital modelling practice until very late in the course would be disastrous.

The written commentary element is intended to encourage a scholarly and thorough approach to the modelling process, and to remind students that, as discussed above, the module is not a beauty contest: though well-made and well-organized models often do appear visually attractive and convincing, the task at hand is to research and propose something about the site of Silchester in a way that passes muster within an ancient world degree, where evidence is always the foundation for argument. The written commentary, which I suggest should function as the 'footnotes' to the model, therefore justifies and explains the choices made in putting the model together: sources of evidence, grounds for conjecture where necessary, comparative material and bibliography consulted, and so on. This was an important part of making this an academically credible module, sitting naturally within an Ancient History or Classics degree program, and in securing the agreement of internal quality assurance and external examiners: the emphasis is on evidence, argument, and analysis as much as on technical software skills, and it is possible to score a high mark for a visually simple but clever and well-argued model.

The model for all students' initial small assessment is of a single structure that I pick. I tend to use the so-called 'church' at Silchester, which is small and fairly simple to model, but admits of an interesting variety of approaches and modes of presentation. The images here show that students can already see the potential of the software for displaying different ways of interpreting and explaining a building by this mid-point of the module. 

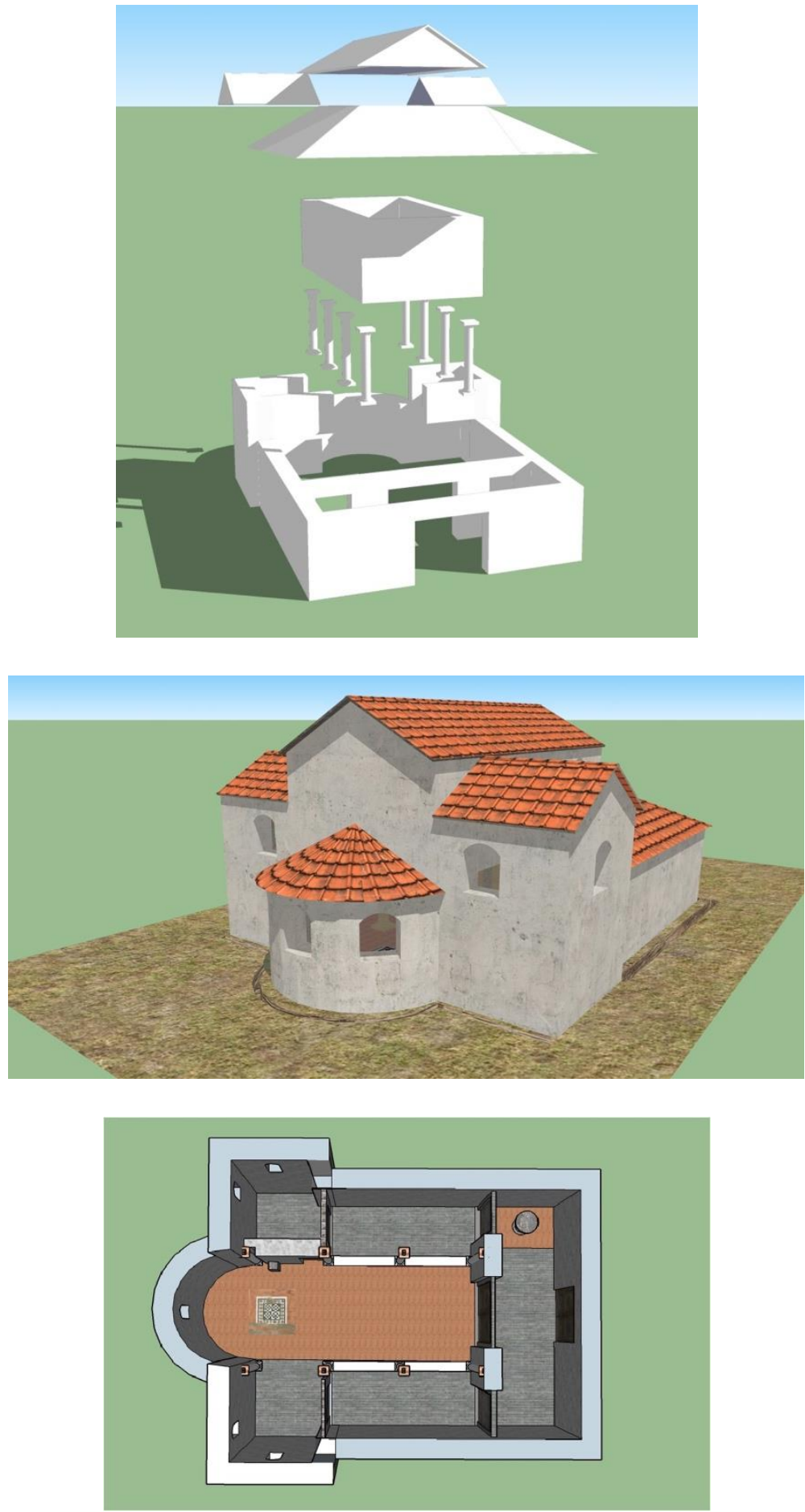

Figure 4: Different views of the so-called 'church' at Silchester, from student models made and viewed in SketchUp. Images courtesy of $3^{\text {rd }}$ year undergraduate students George Jukes and Philip Smither. 
The choice of structure for the second, larger assignment is left to the student, fulfilling the principles of enquiry-based learning. As the examples here show, students are able to create extremely convincing and impressive work after ten weeks of instruction. Ability levels naturally vary, but at the top end of the scale I have awarded higher marks in this module than in any of my other teaching, while - somewhat to my surprise - I have not yet come across a case of complete inability to produce a competent result. Students enjoy SketchUp, grasp the inherent flexibility of digital content, and produce a wide range of imaginative presentations from their models that exceed the brief I give them: I have received animations of change over time, sample lesson plans from an aspirant teacher, 3D printouts, superimpositions of reconstructions on the excavation trench at the site, detailed diagrams of the timber jointing in a Roman roof, and more.

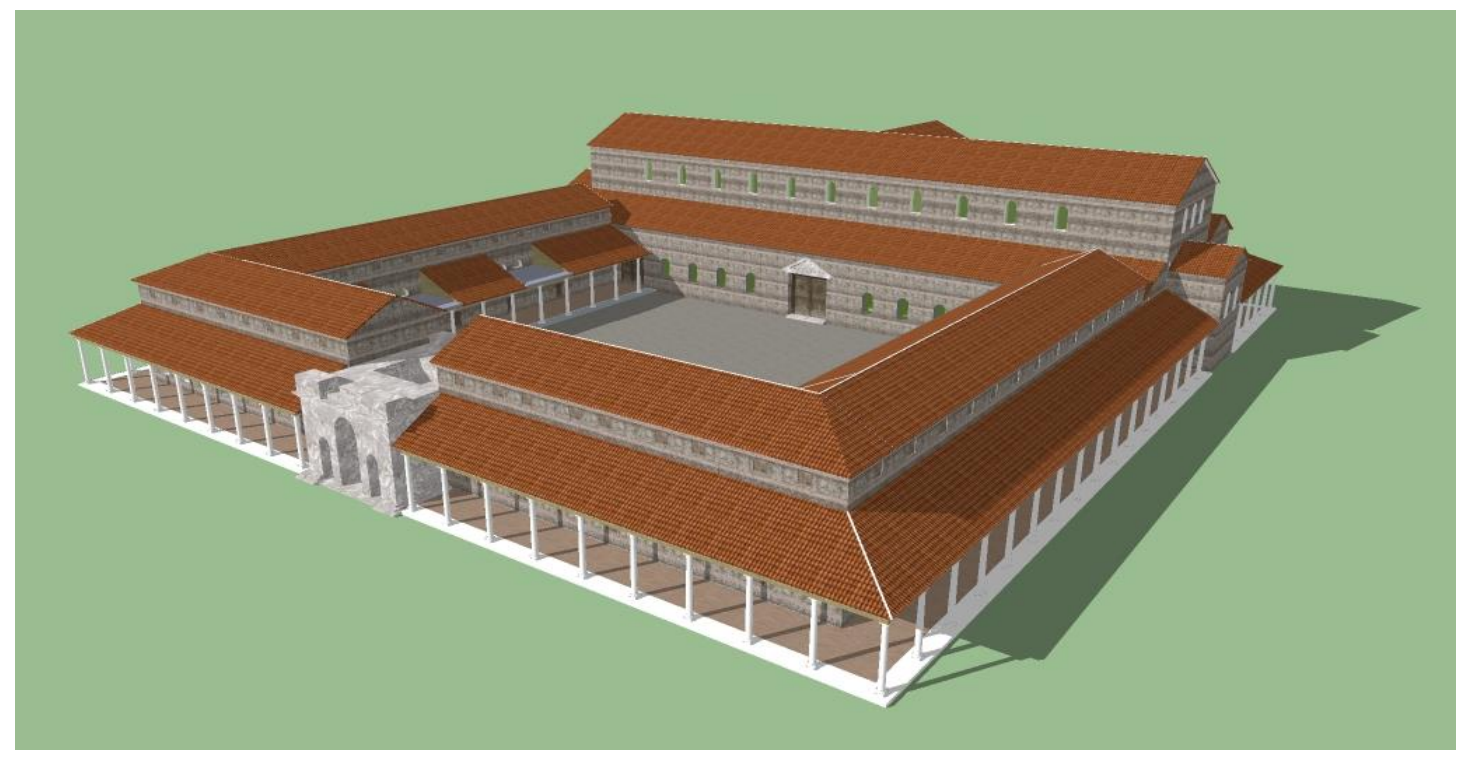




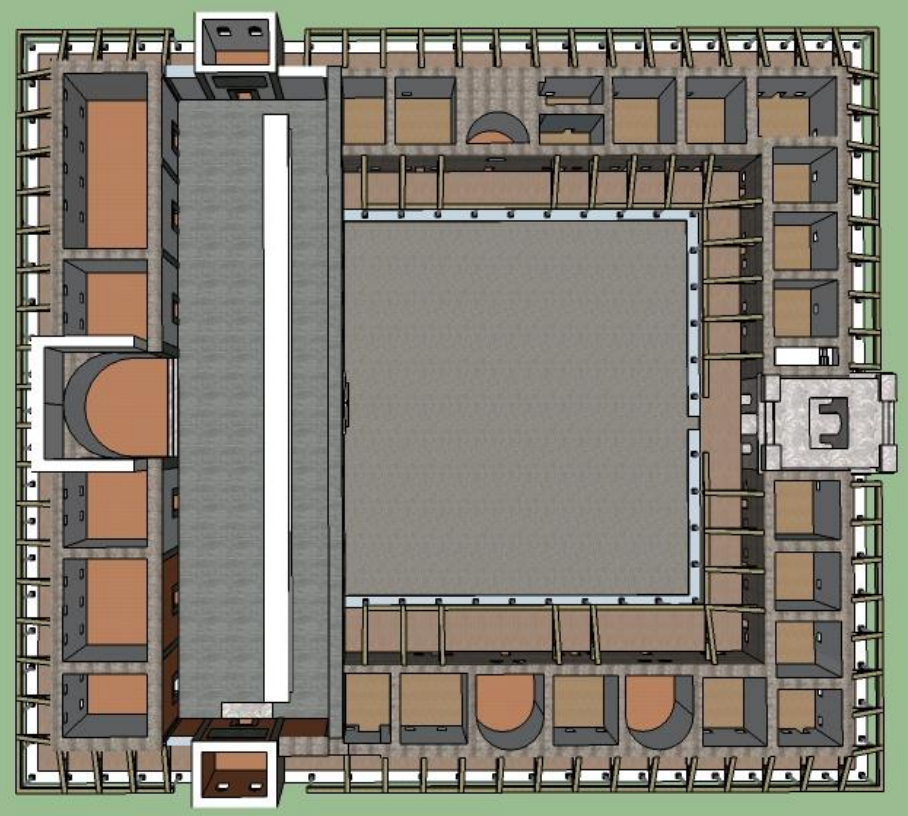

Figure 5: Different views of the Forum-Basilica at Silchester, from a student model made and viewed in SketchUp. Images courtesy of $3^{\text {rd }}$ year undergraduate student George Jukes.

Overall, students have responded very well to the challenge of learning a new way of investigating the ancient world, and seem to have enjoyed doing so. The intuitive user interface of SketchUp has been an important element in the success of the module, but I hope to have shown that some of the principles and modes of enquiry involved can be adapted to other sorts of content, including ready-made online material. The inclusion of $3 \mathrm{D}$ digital content develops valuable digital skills but also encourages new approaches to the traditional questions of evidence and presentation, deepening critical engagement with the way the past is studied and presented.

These questions, and tools, are readily adaptable to a wide variety of pedagogical contexts. We can put ourselves, and our students, in the position of a worshipper at the Panathenaia, of a gladiator in the Colosseum or an actor on the stage of the Theatre of Pompey, of a visitor to the Roman Forum, or the inhabitant(s) of a house in Pompeii, Athens, or Silchester; or we can simply 'pick up' and explore artefacts that are now kept behind glass in London, Paris, or New York. The 
technological tools necessary to do so have never been so easy to use, or so freely and widely available. Classics as a discipline has long been in the vanguard of innovative digital approaches to scholarship, and there is great potential to share these benefits with our students as users and co-creators of worthwhile digital content

A note on image permissions

\begin{tabular}{|c|c|c|}
\hline Figure 1 & $\begin{array}{l}\text { The Colosseum and its surroundings, } \\
\text { looking towards the Esquiline hill - an } \\
\text { image from the author's large digital model } \\
\text { of ancient Rome. } \odot \text { Matthew Nicholls, } \\
\text { University of Reading, } 2018 \text {. }\end{array}$ & $\begin{array}{l}\text { Produced by author for a book by } \\
\text { Nathan Elkins; licensed to his } \\
\text { publisher on a non-exclusive basis, } \\
\text { with copyright remaining with us, and } \\
\text { he has OK'd its reuse here. Should } \\
\text { therefore be fine to use as long as } \\
\text { image licence here is similarly non- } \\
\text { exclusive. }\end{array}$ \\
\hline Figure 2 & $\begin{array}{l}\text { Two views of the same digital model of the } \\
\text { Baths of Diocletian in Rome - an overhead } \\
\text { view superimposed on an aerial image of the } \\
\text { modern city, and a perspectival view } \\
\text { showing height, volume, and elevation } \\
\text { detail. () Matthew Nicholls, University of } \\
\text { Reading, } 2018\end{array}$ & $\begin{array}{l}\text { Digital model content is author's own } \\
\text { and is therefore fine to use. Satellite } \\
\text { photo underlay is from Google Maps- } \\
\text { is this OK to use? If not, should I } \\
\text { replace with Open Streetmap (which } \\
\text { permits reuse under a CC BY-SA } 2.0 \\
\text { licence)? }\end{array}$ \\
\hline Figure 3. & $\begin{array}{l}\text { Two models of the Temple of the Deified } \\
\text { Claudius in Rome, made and viewed in } \\
\text { SketchUp. ( ) Matthew Nicholls, University } \\
\text { of Reading, } 2018\end{array}$ & $\begin{array}{l}\text { Digital model content is author's own } \\
\text { and is therefore fine to use. Written } \\
\text { permission form SketchUp to use their } \\
\text { brand name and imagery of modelling } \\
\text { window secured by email 2.8.18, } \\
\text { subject to sight of this draft. }\end{array}$ \\
\hline Figure 4. & $\begin{array}{l}\text { Different views of the 'church' at Silchester, } \\
\text { from student models made and viewed in } \\
\text { SketchUp. Images courtesy of } 3^{\text {rd }} \text { year } \\
\text { undergraduate students George Jukes and } \\
\text { Philip Smither. }\end{array}$ & $\begin{array}{l}\text { Written permission from both students } \\
\text { secured by email, } 2.8 .18\end{array}$ \\
\hline Figure 5 & $\begin{array}{l}\text { Different views of the Forum-Basilica at } \\
\text { Silchester, from student model made and } \\
\text { viewed in SketchUp. Images courtesy of } 3^{\text {rd }} \\
\text { year undergraduate student George Jukes. }\end{array}$ & $\begin{array}{l}\text { Written permission from both students } \\
\text { secured by email, } 2.8 .18\end{array}$ \\
\hline
\end{tabular}




\section{References}

Boon, G.C. (1974), Silchester: The Roman Town of Calleva, London; David \& Charles.

Craft, J. (2016), 'Rebuilding an Empire with Minecraft: Bringing the Classics into the Digital Space', The Classical Journal, 111.3: 347-364.

Creighton, J. with Fry, R. (2016), Silchester: changing visions of a Roman town. Integrating geophysics and archaeology - the results of the Silchester Mapping Project 2005-10, Britannia Monograph Series, 28, London: Society for the Promotion of Roman Studies.

Nicholls, M.C. (2016), 'Digital visualisation: Ancient Rome, and beyond', British Academy Review 27 (February 2016): 41-44.

Nicholls, M.C. (2018), in Leoussi, A. and Heuser, B. (edd.), Famous Battles and how they shaped the modern world: from Troy to Courtrai, 1200BC - 1302 AD, Barnsley: Pen \& Sword: 81-92.

Ruskin, J. (1857), The Elements of Drawing (2 ${ }^{\text {nd }}$ edition).

Russell, A. (2014), 'Memory and Movement in the Roman Fora from Antiquity to Metro C', Journal of the Society of Architectural Historians, Vol. 73, No. 4 (December 2014): 478-506.

\section{Links (correct at time of writing):}

Ancient world 3D modelling projects:

- www.virtualrome.org - the author's Rome digital modelling project.

- https://www.romereborn.org - another 3D model of ancient Rome..

- http://www.digitales-forum-romanum.de -3D models of the Roman forum at different time periods.

- http://www.byzantium1200.com - a 3D model of Byzantium.

- http://www.amarna3d.com - a 3D model of ancient Amarna in Egypt.

Online resources:

- https://www.futurelearn.com/courses/rome - the author's free five week interactive online course on Rome, using the digital model elements and real-world footage.

- https://www.theguardian.com/higher-education-network/2014/feb/18/winner-universityof-reading-teaching-excellence - Guardian article on the Rome and Digital Silchester projects.

- http://www.londoncharter.org - establishing internationally-recognised principles for the use of computer-based visualisation by researchers, educators and cultural heritage organisations.

Digital tools and software:

- https://sketchfab.com - repository of free 3D content. 
- https://www.kubity.com - platform for sharing 3D models, inc. those made in SketchUp.

- https://www.augment.com/portfolio-items/university-of-reading/ - free tool for Augmented reality, here describing the author's use of the tool with ancient Rome 3D content.

- https://www.sketchup.com - free 3D modelling software. 